Check for updates

Cite this: Mater. Adv., 2022, 3,3490

Received 8th November 2021, Accepted 27th February 2022

DOI: 10.1039/d1ma01043c

rsc.li/materials-advances

\section{Synthesis and characterization of template- mediated mesoporous alumina nanostructures with efficient and fast adsorption of Congo red from aqueous solutions}

\author{
Geetanjali Mishra, (D) $\dagger^{* a b}$ Sanjit Das, (D) $\dagger^{\mathrm{c}}$ Priyalisa Jena ${ }^{\mathrm{a}}$ and Barsha Dash (D) *a
}

\begin{abstract}
This article summaries an approach for the removal of organic dyes like Congo red using mesoporous alumina. Industrial effluents that contain dyes need to be treated before being discharged into surface water. The adsorption method has been established as a successful technique. Mesoporous alumina can be a suitable candidate for this adsorption purpose; so, it has been synthesized by the co-precipitation of aluminium sulphate as the aluminium source and a polysorbate type non-ionic surfactant (Tween-40) as the template. The composite was characterized by XRD, TEM, TG-DTA, etc. The calcined product at $600{ }^{\circ} \mathrm{C}$ was highly porous in nature having a BET surface area of $94 \mathrm{~m}^{2} \mathrm{~g}^{-1}$ as compared to other calcined products. The efficiency of the calcined product towards adsorption of the dye was investigated. This porous alumina out of Tween-40 exhibits excellent adsorption performance for Congo red and the decolourisation efficiency reached $99 \%$ in just $25 \mathrm{~min}$. The adsorption parameters like agitation time, adsorbent dose and dye concentration were also varied. Moreover, the adsorption procedure was studied with various adsorption isotherms like Langmuir and Freundlich isotherms. Equilibrium adsorption data followed both Langmuir and Freundlich isotherms with a maximum multilayer adsorption capacity of $615 \mathrm{mg} \mathrm{g}^{-1}$. Thus, the above porous alumina can act as a promising material for dye adsorption and can reduce pollution in waste water.
\end{abstract}

\section{Introduction}

Hierarchical nano-structured materials have attracted significant research interest in recent years owing to their features and possible applications in the fields of catalysis, ${ }^{1}$ adsorption $^{2}$ and drug delivery ${ }^{3}$ due to their high surface area and thermal stability. Out of different materials, aluminium oxides are broadly used in ceramics, refractories and abrasives due to their hardness, chemical inertness, high temperature resistance, electrical resistance and resistance to oxidation and corrosion. ${ }^{4-6}$ Considering their various properties, synthesis and applications of nano-sized alumina or alumina composites are challenging research topics in the field of materials chemistry.

Different methods had been successfully employed to prepare $\mathrm{g}$-AlOOH and $\mathrm{g}-\mathrm{Al}_{2} \mathrm{O}_{3}$ with micro/nano-structures with various morphologies over the past few decades. ${ }^{7,8}$ Surfactants play a

\footnotetext{
${ }^{a}$ Hydro \& Electrometallurgy Department, CSIR-Institute of Minerals and Materials Technology, Bhubaneswar-751013, India. E-mail: barsha.dash@gmail.com

${ }^{b}$ Department of Metallurgical Engineering \& Materials Science, IIT Bombay, Powai, Mumbai, Maharashtra-400076, India. E-mail: geetanjali1.mishra@gmail.com ${ }^{c}$ School of Materials Sciences, Indian Association for the Cultivation of Science, Kolkata-700032, India

$\dagger$ Authors contributed equally
}

very significant role in the synthesis of $\mathrm{g}-\mathrm{AlOOH} / \mathrm{g}-\mathrm{Al}_{2} \mathrm{O}_{3}$ with various morphologies. ${ }^{3}$ Porous $g-\mathrm{Al}_{2} \mathrm{O}_{3}$ with viable morphologies has been prepared via a facile surfactant (sodium dodecyl sulphate (SDS), cetyl trimethyl ammonium bromide (CTAB), lysine and laurylamine) assisted hydrothermal method ${ }^{9}$ which can significantly improve the function of the alumina-based nanomaterials and broaden the scope of their applications. It is still a challenge to obtain high-quality mesoporous alumina with unique morphology via a facile and efficient approach, which would lead to its new potential applications. environmental effluents produced by different agro industries and textile industries. Azo dyes coming out from various textile industries have become one of the most serious pollutants in the effluents from textile plants ${ }^{10}$ which can contaminate the surface as well as ground water. The improvement in the use of nanomaterials and nanotechnology provides an effective way to solve the current serious problem of environmental pollution because of the distinctive properties of nanomaterials., ${ }^{3,11}$ Various treatments for the removal of azo dyes have been investigated, including adsorption, precipitation, photo degradation, biodegradation, etc. ${ }^{12}$ Among them, the adsorption technique is one of the green technologies to remove the contaminants of water
In current years, substantial attention has been paid to 
caused by the organic/azo dyes. Many researchers have used metal oxides, ${ }^{13}$ activated carbon, ${ }^{14,15}$ polymers, ${ }^{16}$ different porous materials ${ }^{17,18}$ and composite nanomaterials ${ }^{8,19,20}$ to remove toxic heavy metal ions and organic pollutants like azo dyes from waste water. $^{21-23}$ Out of all materials, alumina/g- $\mathrm{Al}_{2} \mathrm{O}_{3}$ is widely used as an adsorbent in sewage treatment and air purification due to its high specific surface area, porosity and good dispersion. ${ }^{3}$ It is necessary to further enhance the adsorption capacity of $\mathrm{g}-\mathrm{Al}_{2} \mathrm{O}_{3}$ by designing the morphology of gamma alumina and adding a pore forming agent.

Herein, we report a facile hydrothermal process to synthesize hierarchical mesoporous g- $\mathrm{Al}_{2} \mathrm{O}_{3}$ with polysorbate-40 (Tween-40) as the template and a pore forming agent to improve its adsorption performance. Adsorption experiments were also compared with those reported in one of the previous studies. ${ }^{6}$ The hierarchical hollow structure can effectively promote the adsorption process under the action of capillary force caused by pores. In addition, the pore forming agent enhances the porosity of the material which is favourable for the adsorption performance. We have investigated the effects of the synthesis conditions on the surface area and particle size of the hierarchical alumina materials. In addition, we have also evaluated the potential of the sample as a highly efficient adsorbent in Congo red adsorption experiments.

\section{Experimental}

\subsection{Materials}

All the chemicals used were of analytical reagent grade and therefore were used directly without further purification. Aluminium sulfate $\left(\mathrm{Al}_{2}\left(\mathrm{SO}_{4}\right)_{3} \cdot 16 \mathrm{H}_{2} \mathrm{O}\right)$ and $\mathrm{NaOH}$ were purchased from Merck, India. Tween-40 was purchased from Sigma Aldrich, India.

\subsection{Synthesis methods}

The samples were synthesized by the co-precipitation method. Briefly, $100 \mathrm{~mL}$ of $1 \mathrm{M} \mathrm{Al}_{2}\left(\mathrm{SO}_{4}\right)_{3}$ was mixed with $10 \mathrm{~mL}$ of $0.1 \mathrm{~N}$ Tween-40 solution. The resulting mixture was maintained at a constant $\mathrm{pH}$ of 5.0 by the dropwise addition of $1 \mathrm{M} \mathrm{NaOH}$. The white precipitate formed was allowed to age at $100{ }^{\circ} \mathrm{C}$ for $4 \mathrm{~h}$. Then it was collected and washed thoroughly with deionized water and finally dried at $45{ }^{\circ} \mathrm{C}$ under vacuum. The above prepared precursor was calcined at different temperatures of $400{ }^{\circ} \mathrm{C}, 500{ }^{\circ} \mathrm{C}, 600{ }^{\circ} \mathrm{C}$ and $900{ }^{\circ} \mathrm{C}$ for $2 \mathrm{~h}$ in a muffle furnace at a heating rate of $10^{\circ} \mathrm{min}^{-1}$ to obtain a mesoporous $\mathrm{Al}_{2} \mathrm{O}_{3}$ material.

\subsection{Characterization studies}

The as synthesized precursor and its calcined samples obtained were characterized using an X-ray diffractometer (XRD) RIGAKU ULTIMA IV in the $2 \theta$ range of 10 to $80^{\circ}$ with a voltage of $30 \mathrm{kV}$ and $\operatorname{CuK} \alpha$. The thermal behavior of the precursor sample was studied using a Mettler-Toledo TGA/SDTA851 ${ }^{\mathrm{e}}$ thermo analyser (TG-DTA) in the temperature range of $25-1000{ }^{\circ} \mathrm{C}$ at a heating rate of $10{ }^{\circ} \mathrm{C} \mathrm{min}^{-1}$ in an air flow $\left(50 \mathrm{~mL} \mathrm{~min}^{-1}\right)$. The morphology of the precursor and the $600{ }^{\circ} \mathrm{C}$ calcined product was studied using a scanning electron microscope (SEM) (Zeiss, EVO 18). High-resolution transmission electron microscopy (TEM) (JEOL-JEM 2100F) was used to obtain chemical and morphological information of the samples. The BrunauerEmmett-Teller (BET) surface area of the powders was analyzed by nitrogen adsorption using a Micromeritics ASAP 2020 nitrogen adsorption apparatus (US). Before nitrogen adsorption measurement, the sample was degassed in a vacuum at $100{ }^{\circ} \mathrm{C}$. Adsorption branches of the isotherms were used to determine the pore size distributions for the samples studied via the Barrett-JoynerHalenda $(\mathrm{BJH})$ method. The volume of nitrogen adsorbed at a relative pressure $\left(P / P_{0}\right)$ of 0.99 was used to determine the pore volume. Average particle sizes of both the precursor and composite materials were measured by using a MICROTRAC DLS-Particle size analyzer.

\subsection{Congo red (CR) removal experiments}

The adsorption of Congo red was carried out to check the efficiency of the material as an adsorbate. In this case the $600{ }^{\circ} \mathrm{C}$ calcined sample can be utilized as efficient adsorbent for $\mathrm{CR}$ removal. To evaluate the adsorption efficiency of the sample, typically, stock solutions of CR (with $400 \mathrm{mg} \mathrm{L}^{-1}, 500 \mathrm{mg} \mathrm{L}^{-1}$, $750 \mathrm{mg} \mathrm{L}^{-1}$ and $1000 \mathrm{mg} \mathrm{L}^{-1}$ ) were prepared in deionized water. Batch experiments were conducted by mixing $50 \mathrm{~mL}$ of the $\mathrm{CR}$ solution of different initial concentrations with $50 \mathrm{mg}$ of the adsorbent at ambient temperature $\left(27^{\circ} \mathrm{C}\right)$ under constant stirring. All the parametric variations such as time and concentration were carried out in individual experiments. The concentration of CR before and after treatment was calculated using a VARIAN Cary 50 Bio UV-Vis spectrophotometer. The characteristic absorption of Congo red at $500 \mathrm{~nm}$ was chosen to monitor the adsorption process. The percentage removal and uptake capacity was determined by using the following equation:

$$
\% \text { Adsorption }=\frac{\left(C_{0}-C_{\mathrm{e}}\right)}{C_{0}} \times 100 .
$$

And the equilibrium uptake was calculated by using eqn (2):

$$
Q_{\mathrm{e}}=\left(C_{0}-\mathrm{C}_{\mathrm{e}}\right) \times V / W
$$

where $C_{0}$ is the initial concentration of the dye solution $\left(\mathrm{mg} \mathrm{L}^{-1}\right)$, $Q_{\mathrm{e}}$ is the equilibrium amount of the dye on the adsorbent $\left(\mathrm{mg} \mathrm{g}^{-1}\right), C_{\mathrm{e}}$ is the equilibrium concentration of the dye solution $\left(\mathrm{mg} \mathrm{L}^{-1}\right), W$ is the weight of the adsorbent $(\mathrm{g})$ used and $V$ is the volume of the dye solution used (L). All experiments have been carried out in triplicates and the results are represented as average readings.

\section{Results and discussion}

\subsection{Structural properties}

The X-ray diffraction (XRD) patterns of the as obtained precursor as well as its different calcined materials are given to indicate the crystal structure of the samples (shown in Fig. 1). The XRD pattern of the as obtained powder matches with the standard XRD pattern of sodium aluminium hydroxide (JCPDS00-051-0529). All the diffraction peaks are similar to those in 


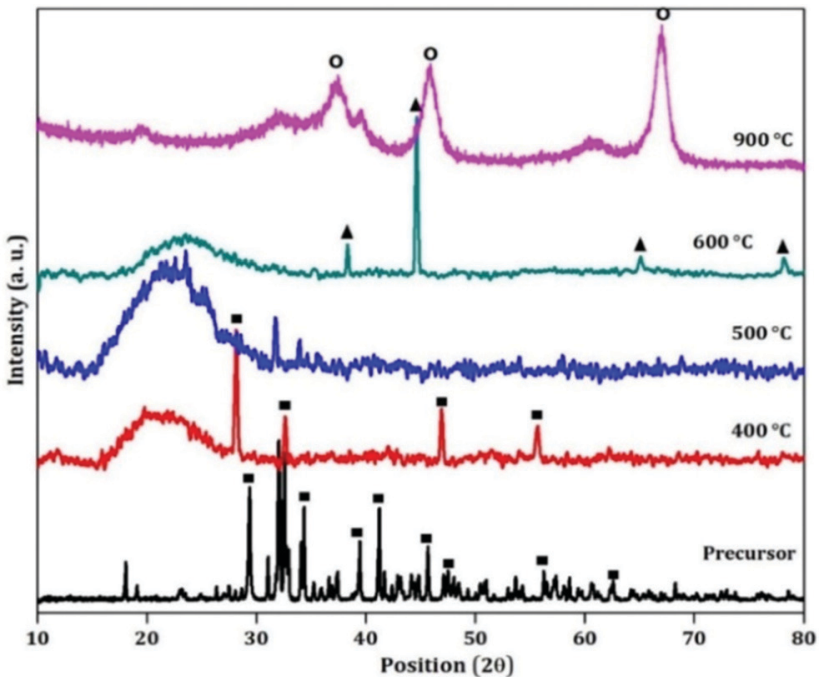

Fig. 1 XRD patterns of the precursor and its different calcined products ( $\mathbf{\square}$ : sodium aluminium hydroxide; $\mathbf{\Lambda}$ : gamma-alumina; O: kappa alumina).

the pattern of sodium aluminium hydroxide which reveals that the crystal structure is well-maintained after the addition of the template. After calcination the material gets converted to an activated state. The XRD patterns are not fully crystalline which can be seen from Fig. 1 . At $600{ }^{\circ} \mathrm{C}$, the XRD pattern of activated alumina matches with the pattern of gamma-alumina (JCPDS00-010-0425). With further calcination to $900{ }^{\circ} \mathrm{C}$, the phase of alumina changes from gamma to kappa (JCPDS-00-013-0373).

Therefore in this case the transformation of aluminium hydroxide with temperature is aluminium hydroxide $\rightarrow$ gamma alumina $\rightarrow$ kappa alumina.

The 3D structure of the precursor is given in Fig. 2(a). The packing is in the direction along the $c$-axis as can be seen from the figure. Therefore Tween- 40 which was added to the system as the template, got coated on the surface as well as in the interlayer space (revealed in Fig. 2(b)). After calcination at $600{ }^{\circ} \mathrm{C}$, the surface water, the water molecules present inside the layers as well as the surfactant or template incorporated

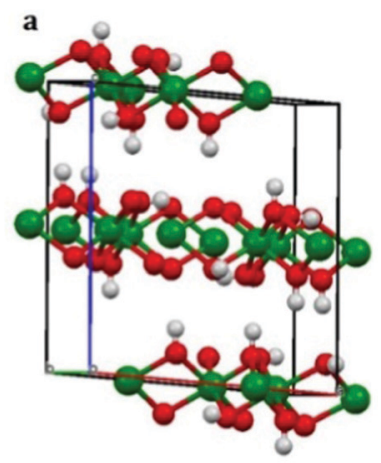

b


Fig. 2 3D model of (a) packing of the precursor showing co-ordinate axes and (b) incorporation of Tween-40 in aluminium hydroxide layers.
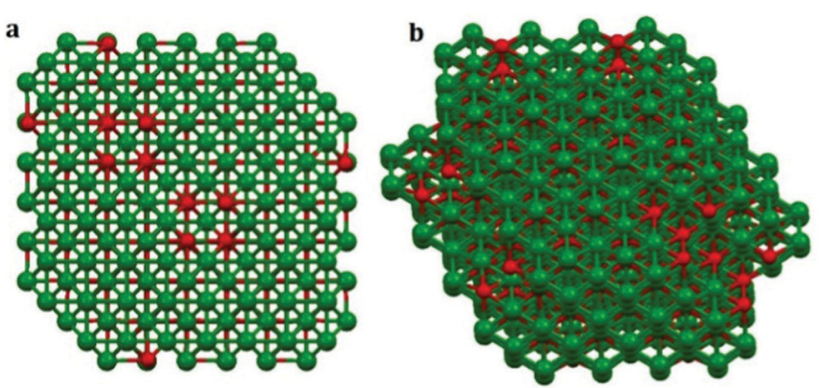

Fig. 3 3D model of gamma alumina obtained by calcination of the precursor at $600{ }^{\circ} \mathrm{C}$; (a) and (b) are views along different axes of the compound.

i.e. Tween-40 got decomposed leading to a cage like structure of gamma alumina along with lots of pores inside the cage as shown in Fig. 3(a and b).

\subsection{Thermal analysis}

The thermal analysis of the composite material was carried out to check the mass loss with the increase in temperature and the result is picturized in Fig. 4 . The mass loss of the material is as follows; up to $200{ }^{\circ} \mathrm{C}$, the mass loss is due to physisorbed and chemisorbed water molecules. After $400{ }^{\circ} \mathrm{C}$, the surfactant will decompose to carbon dioxide and water which shows an endothermic peak in DTA plot. Finally alumina is formed at a temperature of around $1000{ }^{\circ} \mathrm{C}$.

\subsection{Morphological analysis}

The morphology of the precursor and the $600{ }^{\circ} \mathrm{C}$ calcined product is characterized using a scanning electron microscope (SEM), presented in Fig. 5. It can be observed that precursor particles are approximately spherical shaped and in an agglomerated form (Fig. 5(a)). After calcination at $600{ }^{\circ} \mathrm{C}$, the template got decomposed and therefore the particle size decreased, which means the particles got shrinked and a chain like bonding formed between $\mathrm{Al}-\mathrm{O}-\mathrm{Al}$ which can be evidenced from Fig. 5(b).

The TEM images of the samples exhibit nano sized particlelike structures as precursors as revealed in Fig. 6. The SAED

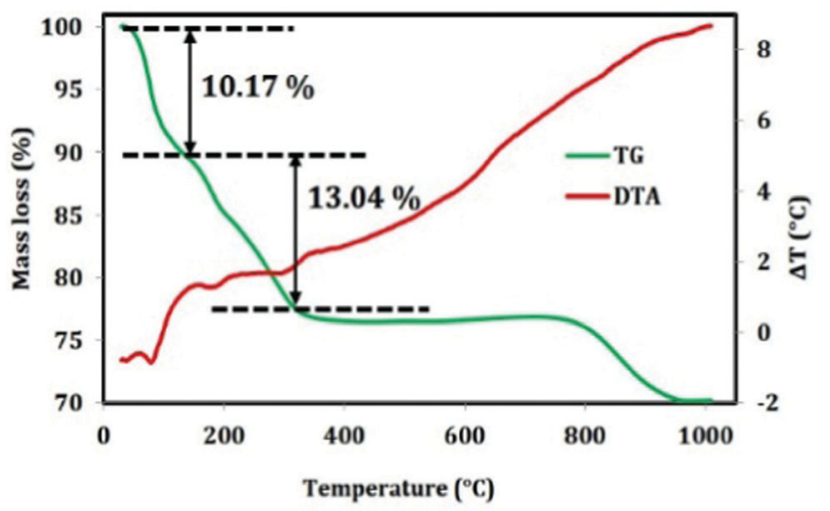

Fig. 4 Thermal analysis of Tween-40 mediated aluminium hydroxide. 


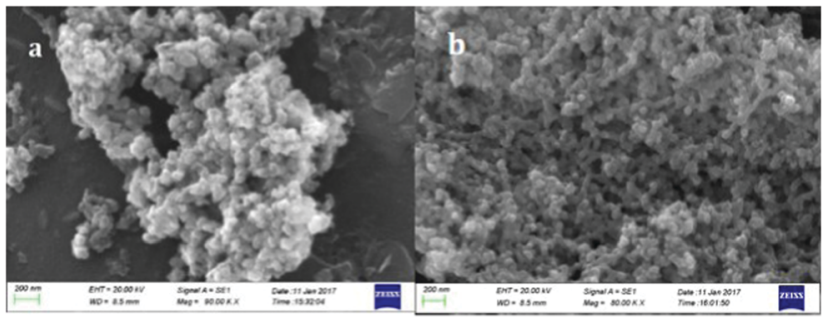

Fig. 5 SEM image of (a) the precursor material incorporated with the template, and (b) SEM image of the $600^{\circ} \mathrm{C}$ calcined material.

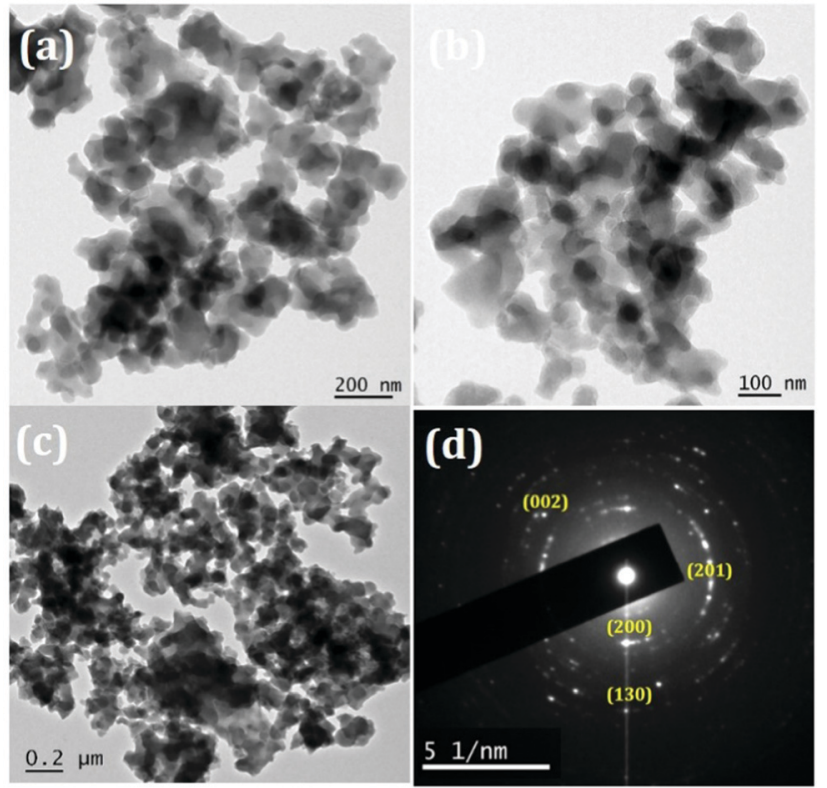

Fig. 6 TEM image $(\mathrm{a}-\mathrm{c})$ of the precursor material and the corresponding SAED pattern $(d)$

patterns (Fig. 6(d)) are corroborating with the corresponding XRD patterns of the precursors (JCPDS-00-051-0529). After thermal treatment at $600{ }^{\circ} \mathrm{C}$, particles became porous because of the decomposition of the added surfactant as well as the removal of intra molecular and interstitial water (Fig. 7). Porosity of the material can be visualized clearly in Fig. 7(a-c) and the amorphous nature can be seen from the SAED pattern (provided in Fig. 7(d)) which matches with the XRD pattern.

\subsection{Particle size analysis}

The particle size variation with increase in temperature follows the same trend for both the materials and therefore for the sake of simplicity only one picture is given. With increase in temperature, the particle size decreases to the nano range as revealed in Fig. 8. The original material has an average particle size of 6.5 micron and after calcination at $400{ }^{\circ} \mathrm{C}$, the particle size distribution becomes slightly broader indicating the addition of smaller particles to the distribution. The average particle size is provided in Table 1.

Then on increasing the temperature to $500{ }^{\circ} \mathrm{C}$, the average particle size decreases to 4.6 microns and a further increase in

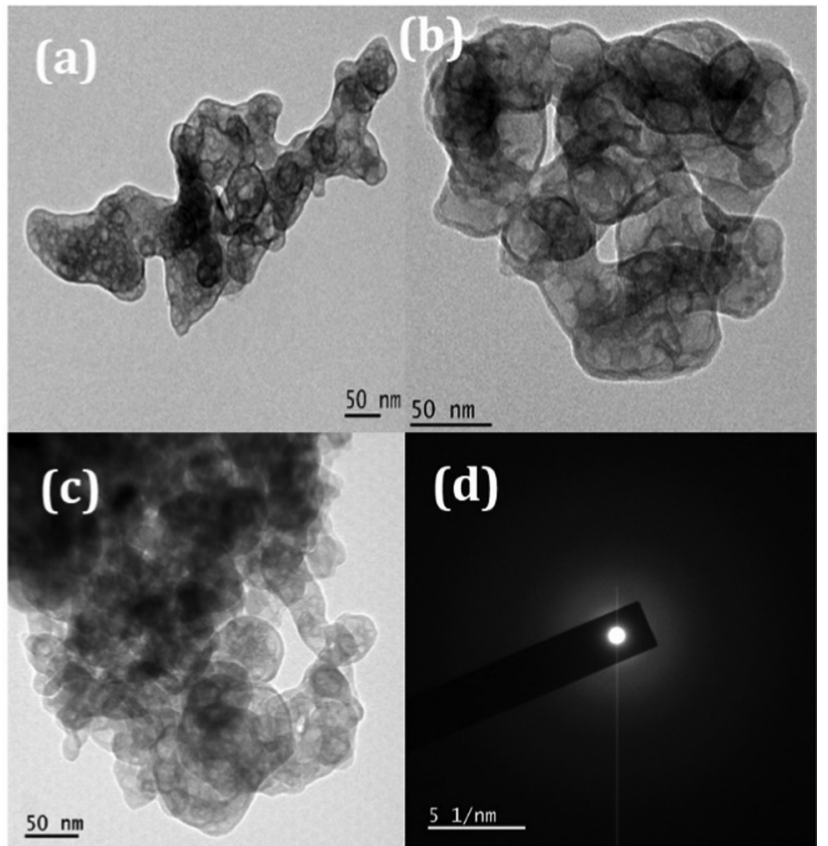

Fig. 7 TEM image $(\mathrm{a}-\mathrm{c})$ of the $600{ }^{\circ} \mathrm{C}$ calcined material and the corresponding SAED pattern (d)

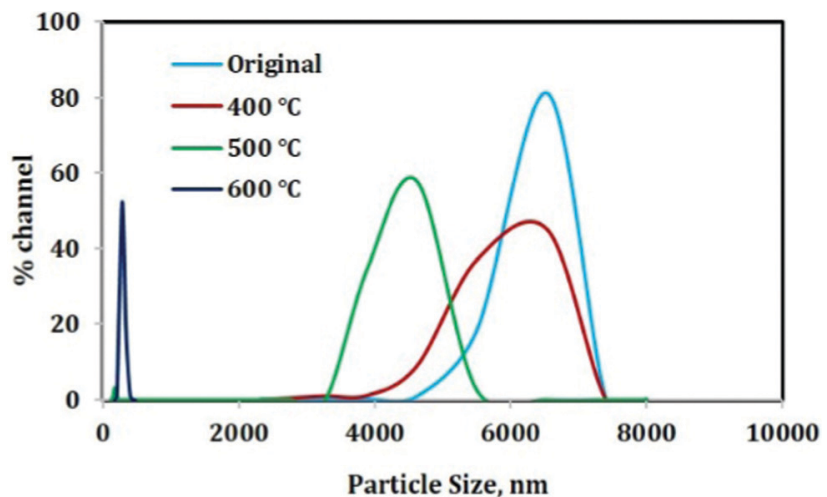

Fig. 8 Particle size distribution of the precursor and its different calcined materials.

temperature to $600{ }^{\circ} \mathrm{C}$ results in the decrease in particle size to $243 \mathrm{~nm}$. This decrease in particle size ultimately results in a high surface area (high surface/volume ratio) which will help in the case of adsorption. Therefore the $600{ }^{\circ} \mathrm{C}$ calcined material can be an efficient material for adsorption purpose.

Table 1 Average particle size of the sample calcined at different temperatures

\begin{tabular}{ll}
\hline Samples & Average particle size $(\mathrm{nm})$ \\
\hline Original & 6540 \\
$400{ }^{\circ} \mathrm{C}$ calcined & 5540 \\
$500{ }^{\circ} \mathrm{C}$ calcined & 4620 \\
$600{ }^{\circ} \mathrm{C}$ calcined & 243
\end{tabular}




\subsection{Surface area analysis}

The BET surface area obtained through nitrogen adsorptiondesorption isotherms and $\mathrm{BJH}$ pore size distribution of different calcined samples (i.e. $400{ }^{\circ} \mathrm{C}, 500{ }^{\circ} \mathrm{C}, 600{ }^{\circ} \mathrm{C}$ and $900{ }^{\circ} \mathrm{C}$ ) are given in Fig. 9. As shown in the figure, all the isotherms exhibit type-IV isotherm which is the characteristic of mesoporous materials $^{24}$ along with a H1-type hysteresis loop which is associated with well-defined cylindrical-like pore channels or uniform spheres ${ }^{24}$ except that shown in Fig. 9(d).

Comparing the isotherm of $400{ }^{\circ} \mathrm{C}, 500{ }^{\circ} \mathrm{C}$ and $600{ }^{\circ} \mathrm{C}$, the height of the isotherm is almost the same for $400{ }^{\circ} \mathrm{C}$ and $500{ }^{\circ} \mathrm{C}$ (Fig. 9(a and b)) but it is highest in the case of $600{ }^{\circ} \mathrm{C}$ (Fig. 9(c)), confirming the maximum quantity of adsorbed nitrogen in the $600{ }^{\circ} \mathrm{C}$ sample. The corresponding pore size distributions of each of the samples are given in inset of each figures. The data listed in Table 2 demonstrate that the BET surface area of the $600{ }^{\circ} \mathrm{C}$ calcined sample $\left(94.302 \mathrm{~m}^{2} \mathrm{~g}^{-1}\right)$ is more than that of the $400{ }^{\circ} \mathrm{C}$ and $500{ }^{\circ} \mathrm{C}$ calcined samples $\left(49.54 \mathrm{~m}^{2} \mathrm{~g}^{-1}\right.$ and $58.1707 \mathrm{~m}^{2} \mathrm{~g}^{-1}$ respectively). The total pore volume of the $600{ }^{\circ} \mathrm{C}$ calcined sample is also slightly more than that of the $400{ }^{\circ} \mathrm{C}$ and $500{ }^{\circ} \mathrm{C}$ calcined samples (shown in Table 2). From our previous work, it can be compared that porous alumina out of aluminium hydroxide along with sodium lauryl sulphates (SLS) has a lesser surface area $\left(42 \mathrm{~m}^{2} \mathrm{~g}^{-1}\right)$ than that obtained this time $\left(94.302 \mathrm{~m}^{2} \mathrm{~g}^{-1}\right){ }^{6}$

During calcination, the material first loses physisorbed and chemisorbed water molecules which results in a mass loss of
Table 2 BET surface area, BJH pore volume and average pore diameter of different calcined samples

\begin{tabular}{llll}
\hline Samples & $\begin{array}{l}\text { BET surface } \\
\text { area }\left(\mathrm{m}^{2} \mathrm{~g}^{-1}\right)\end{array}$ & $\begin{array}{l}\text { Pore volume } \\
\left(\mathrm{cm}^{3} \mathrm{~g}^{-1}\right)\end{array}$ & $\begin{array}{l}\text { Average pore } \\
\text { diameter }(\mathrm{nm})\end{array}$ \\
\hline $400{ }^{\circ} \mathrm{C}$ calcined & 49.54 & 0.435 & 37.4923 \\
$500{ }^{\circ} \mathrm{C}$ calcined & 58.1707 & 0.496 & 45.2465 \\
$600{ }^{\circ} \mathrm{C}$ calcined & 94.302 & 0.586 & 47.11 \\
$900{ }^{\circ} \mathrm{C}$ calcined & 2.491 & 0.109 & 0.1219
\end{tabular}

the material (given in Fig. 4) and after this the surfactant will decompose leaving pores in the material which also can be seen in the cage like structure with sheet-like surface and pores in Fig. 3. At $600{ }^{\circ} \mathrm{C}$ perhaps all the surfactants got decomposed and therefore the pore volume is more in this case (given in Table 2).

By calcining the material to $900{ }^{\circ} \mathrm{C}$, the material gets converted to the oxide phase completely and all the anions and added surfactant are decomposed prior to $900{ }^{\circ} \mathrm{C}$. Therefore the porosity shrinks showing no distribution (given in the inset of Fig. 9(d)) and simultaneously the sample shows a type-III adsorption-desorption plot (given in Fig. 9(d)) which is the characteristic of a nonporous material. ${ }^{24}$ This type of comparison has not been reported in any of the manuscripts.

It is a well-known fact that the lesser the particle size, the more is the surface area and hence more will be the surface adsorption capacity of the material. Though all the three
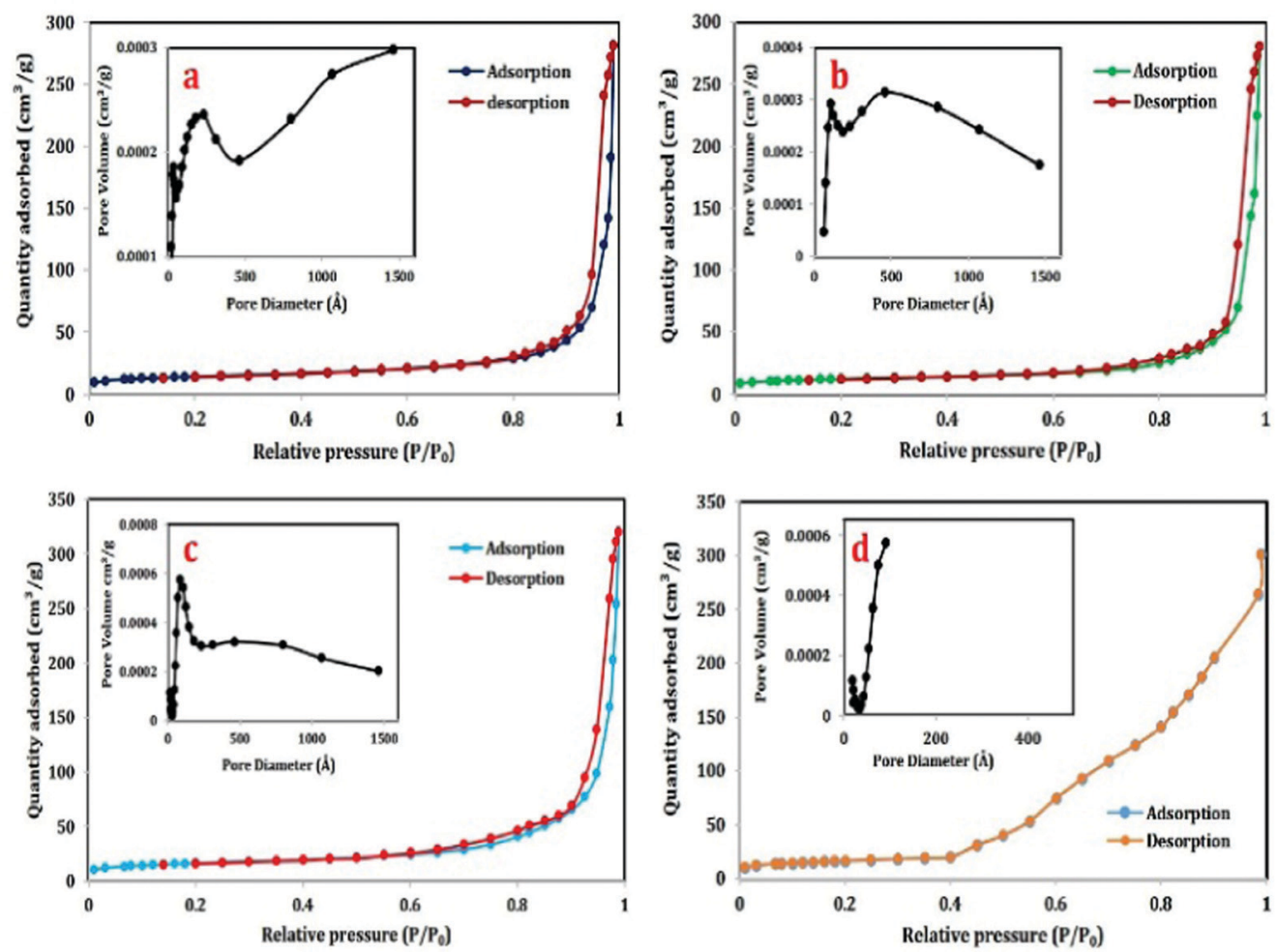

Fig. $9 \mathrm{~N}_{2}$ adsorption-desorption isotherm of different calcined samples; (a) $400{ }^{\circ} \mathrm{C}$ calcined sample, (b) $500{ }^{\circ} \mathrm{C}$ calcined sample, (c) $600{ }^{\circ} \mathrm{C}$ calcined sample, and (d) $900{ }^{\circ} \mathrm{C}$ calcined sample. The inset indicates the pore size distribution of the sample calculated from the adsorption branch by the BJH model. 
materials i.e. $400{ }^{\circ} \mathrm{C}, 500{ }^{\circ} \mathrm{C}$ and $600{ }^{\circ} \mathrm{C}$ show almost a similar adsorption-desorption isotherm, the height of the $600{ }^{\circ} \mathrm{C}$ calcined sample is higher (Fig. 9(c)) confirming the more adsorption capacity.

It has also a lesser particle size (given in Fig. 8), high BET surface area and high pore volume as compared to the $400{ }^{\circ} \mathrm{C}$ and $500{ }^{\circ} \mathrm{C}$ calcined samples. All these characteristics make the sample a promising adsorbent material.

\subsection{Mechanism of the formation of hierarchical hollow structures and kappa alumina}

Based on the above results, a plausible growth process of the hollow structure is anticipated (Fig. 10).

$\mathrm{Al}_{2}\left(\mathrm{SO}_{4}\right)_{3}$ will be in the form of $\left[\mathrm{Al}\left(\mathrm{OH}_{2}\right)_{6}\right]^{3+}$ when present in solution and with an increase in $\mathrm{pH}$, gradual hydrolysis occurs as given below: ${ }^{25}$

$$
\left[\mathrm{Al}\left(\mathrm{OH}_{2}\right)_{6}\right]^{3+}+2 \mathrm{H}_{2} \mathrm{O} \rightarrow\left[\mathrm{Al}(\mathrm{OH})_{h}\left(\mathrm{OH}_{2}\right)_{6-h}\right]^{(3-h)^{+}}+h \mathrm{H}_{3} \mathrm{O}^{+}
$$

$$
\left[\mathrm{Al}(\mathrm{OH})_{h}\left(\mathrm{OH}_{2}\right)_{6-h}\right]^{(3-h)^{+}} \rightarrow \mathrm{AlOOH} \rightarrow \mathrm{Al}_{2} \mathrm{O}_{3}
$$

where $h$ is the molar ratio of $\mathrm{OH}$ to $\mathrm{Al}(\mathrm{OH}: \mathrm{Al})$.

Amorphous polynuclear hydroxides or oxy-hydroxides will be formed by the polymerization of hydrolysis products via olation and oxolation. ${ }^{26}$ The structure or morphology of the metastable hydrolyzed products is dependent on the various experimental parameters ( $\mathrm{pH}$, time, temperature, etc.). Initially, because of the slower addition of $\mathrm{NaOH}$ solution, $\mathrm{OH}^{-}$ions got released and enhanced $\mathrm{Al}^{3+}$ hydrolysis resulting in the synthesis of metastable alumina compounds. ${ }^{25,27}$ During the growth of the metastable products, electrostatic interactions happened between the surface hydroxyl group and the Tween40 chains. On calcining the sample at moderate temperatures, the amorphous aluminium (oxy)hydroxides got aged and removal of the template i.e. tween-40 occurred leaving behind the hierarchical hollow g-AlOOH (given in Fig. 7(a-c)). Further calcination at high temperature leads to the complete removal of the organic matters from the sample followed by the shrinkage of the crystal forming a new phase i.e. kappa- $\mathrm{Al}_{2} \mathrm{O}_{3}$ (represented in XRD patterns in Fig. 1).

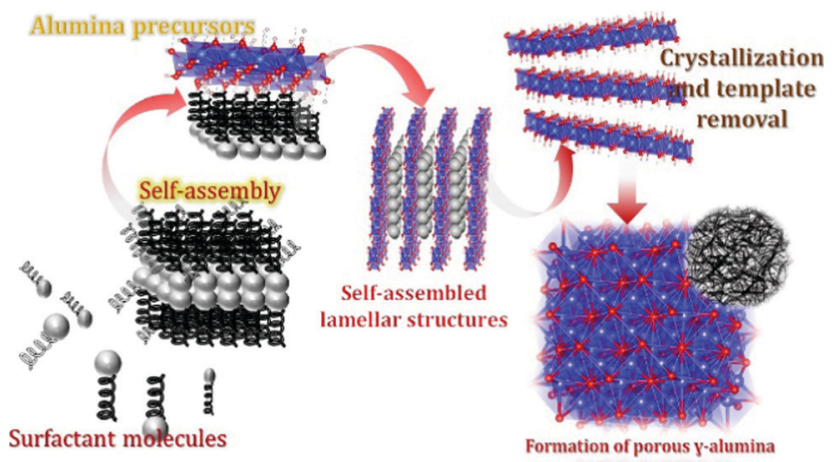

Fig. 10 Schematic illustration of the formation mechanism of hierarchical hollow aluminium (oxy)hydroxides.

\subsection{Adsorption performance towards Congo red}

Activated alumina is now-a-days used mainly for catalysis and adsorption purpose because of its large surface area and higher porosity. In this experiment, the adsorption properties were studied by taking different calcined products and taking congo red as the dye. $50 \mathrm{mg}$ of alumina powder of different calcined temperatures i.e. at $400{ }^{\circ} \mathrm{C}, 500{ }^{\circ} \mathrm{C}$ and $600{ }^{\circ} \mathrm{C}$ was tested against Congo red solutions $(50 \mathrm{~mL})$ with different concentrations at $27^{\circ} \mathrm{C}$.

After $30 \mathrm{~min}$, UV-Vis absorption spectroscopy measurement was performed to determine the remaining dye concentration after adsorption and accordingly $C / C_{0}$ was determined $\left(C_{0}\right.$ and $C$ represent the initial concentration of Congo red and the remaining concentration after treatment, respectively). The details of UV-Vis measurement are given in Fig. 11(a). From the results it can be evidenced that out of the $400{ }^{\circ} \mathrm{C}, 500{ }^{\circ} \mathrm{C}$ and $600{ }^{\circ} \mathrm{C}$ calcined products of Tween-40-activated alumina, the $600{ }^{\circ} \mathrm{C}$ calcined material is an efficient material for adsorption kind of experiments as it leaves less concentration of the dye after adsorption experiments as compared to other two materials and ultimately $C / C_{0}$ is also less.

The reason behind this is the increase in the calcination temperature at which all the adsorbed water molecules as well as the template i.e. Tween-40 are decomposed completely leaving pores. In the case of $400{ }^{\circ} \mathrm{C}$ and $500{ }^{\circ} \mathrm{C}$ calcined materials, complete decomposition of the template is perhaps not possible and therefore the adsorption efficiency is somewhat less as compared to that of the $600{ }^{\circ} \mathrm{C}$ calcined material. Another reason is the high surface area and pore volume of the sample (as evidenced from Table 2), as well as the lower particle size of the material (as evidence from Table 1). Therefore the $600{ }^{\circ} \mathrm{C}$ calcined material of Tween-40-activated alumina was considered for further adsorption experiments.

By fixing the concentration of Congo red at $500 \mathrm{mg} \mathrm{L}^{-1}$, the kinetics study of adsorption was carried out i.e. the adsorption rate of $500 \mathrm{mg} \mathrm{L}^{-1}$ Congo red solution on porous alumina was investigated. $50 \mathrm{mg}$ of $600{ }^{\circ} \mathrm{C}$ calcined activated alumina powder was added to $50 \mathrm{~mL}$ of $500 \mathrm{mg} \mathrm{L}^{-1}$ Congo red solution at $27{ }^{\circ} \mathrm{C}$. The absorbance maxima of Congo red is at $500 \mathrm{~nm}$ (as shown in Fig. 11(b)). After a 5 min interval, the \% of absorbance decreases to around $50 \%$ i.e. after $5 \mathrm{~min}$ the concentration of the remaining dye is $60 \mathrm{mg} \mathrm{L}^{-1}$ from the initial concentration of $500 \mathrm{mg} \mathrm{L}^{-1}$. After $25 \mathrm{~min}$, the \% of absorbance decreases to $10 \%$ (the corresponding concentration is $2.2 \mathrm{mg} \mathrm{L}^{-1}$ ) and after $30 \mathrm{~min}$, the further decrease in absorbance confirms the removal of Congo red dye after 30 min giving a clear transparent solution (inset of Fig. 11(b)).

The effect of the initial concentration of Congo red on adsorption capacity of mesoporous activated alumina with time was further investigated to show how good the sample is for removing the pollutant (given in Fig. 12).

The results illustrate that the sample can remove most of the Congo red with high concentration $\left(1000 \mathrm{mg} \mathrm{L}^{-1}\right)$ in a short time. Trials were made to adsorb $750 \mathrm{mg} \mathrm{L}^{-1}$ and $1000 \mathrm{mg} \mathrm{L}^{-1}$ of Congo red solution using $50 \mathrm{mg}$ of the sample. The ultimate observation is given in Fig. 12(a and b). After $30 \mathrm{~min}$, 

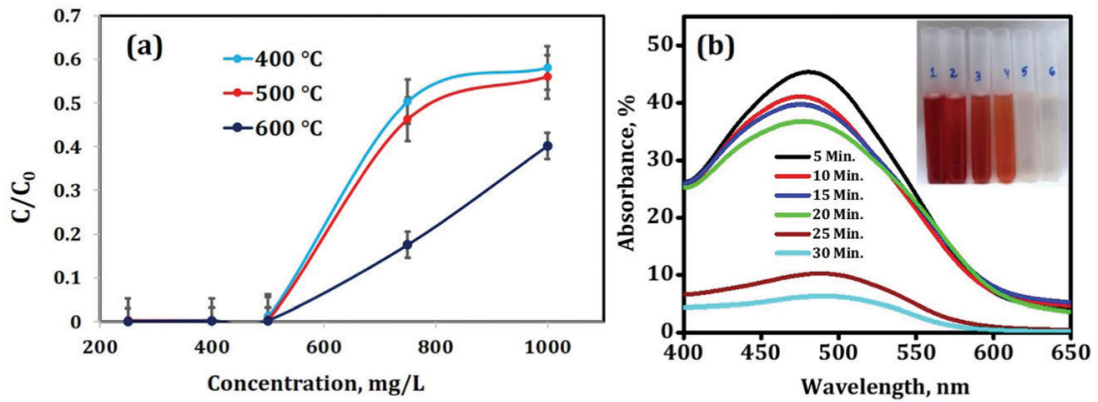

Fig. 11 (a) Rate of adsorption by varying the temperature of Tween-40-activated alumina against different concentrations of Congo red; (b) absorption spectra of Congo red in the presence of mesoporous activated alumina $\left(600^{\circ} \mathrm{C}\right.$ ) after time intervals of $5,10,15,20,25$ and 30 min; (inset) photographs of the remaining concentration of Congo red at different time intervals.

$131 \mathrm{mg} \mathrm{L^{-1 }}$ and $401.5 \mathrm{mg} \mathrm{L}^{-1}$ of Congo red remains in the solution out of $750 \mathrm{mg} \mathrm{L}^{-1}$ and $1000 \mathrm{mg} \mathrm{L}^{-1}$, respectively. The percentage of adsorption for 400 and $500 \mathrm{mg} \mathrm{L}^{-1}$ is $100 \%$ after $25 \mathrm{~min}$, whereas for higher concentrations of $\mathrm{CR}$, i.e., for 750 and $1000 \mathrm{mg} \mathrm{L}^{-1}$, maximum get adsorbed within 30 minutes. For the rest period slight improvement in adsorption was observed as shown in Fig. 12(b). This ideal adsorption capacity of the material is very high as compared to the data available in the literature for other alumina. ${ }^{10,11}$

\subsection{Adsorption isotherms}

The adsorption isotherm describes the relationship between the adsorbate at a constant temperature and its equilibrium concentration. The information of distribution of dye molecules over the adsorbent during the adsorption process under equilibrium conditions can be obtained from the adsorption isotherms. Different adsorption isotherms were studied like Langmuir and Freundlich to describe the adsorption equilibrium of the adsorbent at different initial concentrations of Congo red (620, 625, 630, 635 and $640 \mathrm{mg} \mathrm{L}^{-1}$ ) for $60 \mathrm{~min}$. The adsorption capacity of the adsorbent is based on the porosity and surface area of the adsorbent as well as the interaction of the functional groups of the adsorbate. ${ }^{28}$

Langmuir isotherm adopts the adsorption of the adsorbate on the active sites of the homogeneous surface of the adsorbent in monolayer distribution. ${ }^{28,29}$ The linear form of Langmuir isotherm is expressed in eqn (5):

$$
C_{\mathrm{e}} / Q_{\mathrm{e}}=1 / K_{\mathrm{L}}+C_{\mathrm{e}} \cdot a_{\mathrm{L}} / K_{\mathrm{L}}
$$

where $C_{\mathrm{e}}\left(\mathrm{mg} \mathrm{L}^{-1}\right)$ is the equilibrium concentration, $Q_{\mathrm{e}}\left(\mathrm{mg} \mathrm{g}^{-1}\right)$ is the amount of CR adsorbed on unit mass of the adsorbent at equilibrium, and the parameters $a_{\mathrm{L}}\left(\mathrm{L} \mathrm{mg}^{-1}\right)$ and $K_{\mathrm{L}}\left(\mathrm{L} \mathrm{g}^{-1}\right)$ are the Langmuir constants; $K_{\mathrm{L}} / a_{\mathrm{L}}\left(\mathrm{mg} \mathrm{g}^{-1}\right)$ is the capacity factor of maximum adsorption $\left(Q_{\max }\right)$ that relates to $Q_{\mathrm{e}}$ for a complete monolayer and energy of adsorption, respectively. These constants were calculated from the linear plot of $C_{\mathrm{e}} / Q_{\mathrm{e}}$ versus $C_{\mathrm{e}}$ as given in Fig. 13(a). The $R^{2}$ value (i.e. square of correlation coefficient) of Langmuir adsorption isotherm is found to be 1 (revealed from Fig. 13(a)) and shows linearity indicating the adsorption is monolayer in nature.

Freundlich isotherm gives the relationship between equilibrium liquid and solid phase capacity based on multilayer adsorption (a heterogeneous surface). This isotherm is derived from the assumption that the adsorption sites are distributed exponentially with respect to the heat of adsorption and is given by eqn (6):

$$
\ln Q_{\mathrm{e}}=\ln a_{\mathrm{f}}+b_{\mathrm{f}} \ln C_{\mathrm{e}}
$$

where $a_{\mathrm{f}}\left(\mathrm{mg} \mathrm{g}^{-1}\right)$ indicates the multilayer adsorption capacity and $b_{\mathrm{f}}$ is an empirical parameter related to the intensity of adsorption. The plot of $\ln Q_{\mathrm{e}} v s . \ln C_{\mathrm{e}}$ is illustrated in Fig. 13(b). The slope and intercept represent $b_{\mathrm{f}}$ and $\ln a_{\mathrm{f}}$, respectively.

The $R^{2}$ value of Freundlich adsorption isotherm is found to be 0.9906 (revealed from Fig. 13(b)) and shows almost linearity indicating the adsorption is multilayer in nature. The maximum adsorption capacity is $615 \mathrm{mg} \mathrm{g}^{-1}$ which is much higher than those reported in the previous literature, presented in
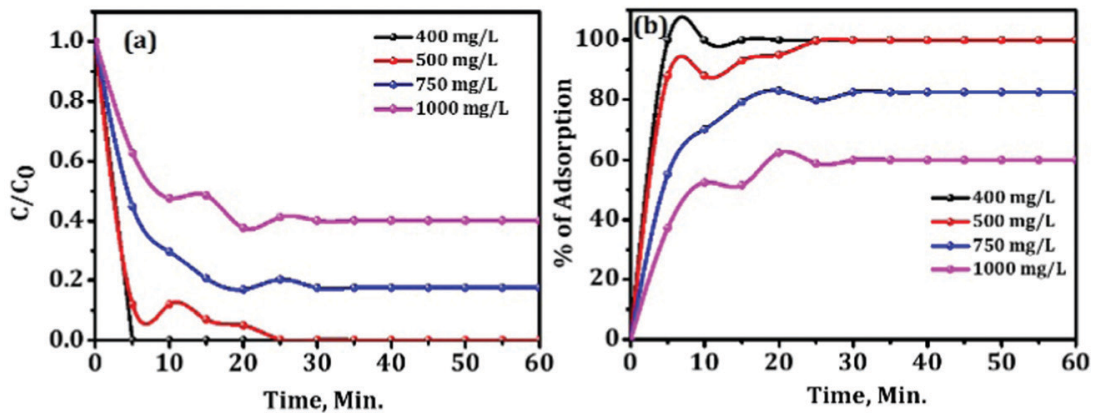

Fig. 12 Rate of adsorption of the $600^{\circ} \mathrm{C}$ activated alumina against different concentrations of Congo red. 

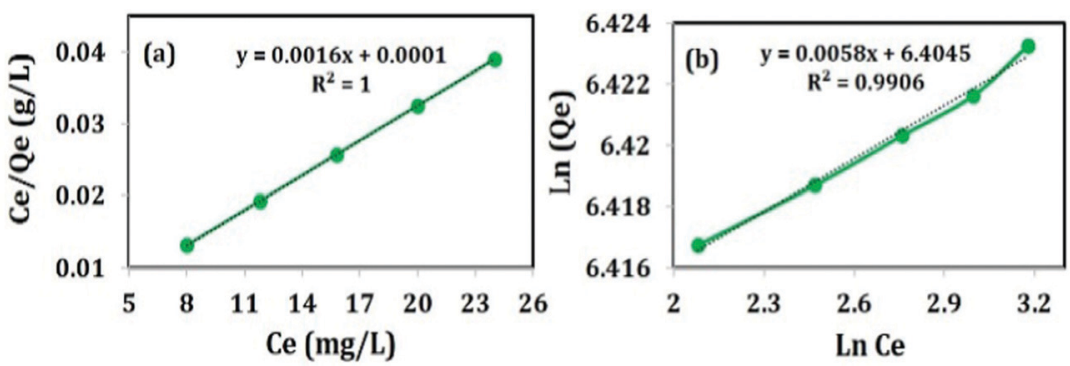

Fig. 13 Adsorption isotherms; (a) Langmuir adsorption isotherm and (b) Freundlich adsorption isotherm.

Table 3. The high $Q_{\max }$ is attributed to the huge specific surface area and long chain structure of Tween- 40 which left the material mesoporous after calcination and could promote surface complexation and ion-exchange. High temperature calcination (i.e. at $600{ }^{\circ} \mathrm{C}$ ) improves the adsorption capacity of the sample by the removal of Tween-40. Most importantly, the calcined sample has the capacity of removing $60 \%$ of $\mathrm{CR}$ from $1000 \mathrm{mg} \mathrm{L}^{-1}$ solution (as revealed in Fig. 13(b)).

\subsection{Adsorption kinetics}

The kinetic behavior of mesoporous alumina has been investigated using both pseudo first-order and pseudo-second-order kinetics models. Pseudo first-order kinetics model is expressed as follows:

$$
\log \left(q_{\mathrm{e}}-q_{t}\right)=\log \left(q_{\mathrm{e}}\right)-\left(k_{2} t\right) / 2.303
$$

where $k_{2}$ is the pseudo-first-order rate constant, and $q_{\mathrm{e}}$ and $q_{t}$ are the capacity of adsorption of Congo red molecules onto mesoporous alumina at equilibrium and time $t$, respectively. The values of $k_{2}$ and $q_{\mathrm{e}}$ were calculated from the slope and intercept of the plot of $\log \left(q_{\mathrm{e}}-q_{t}\right) v s . t$ and are listed in Table 4 . It can be seen from Table 4 that the estimated $q_{\mathrm{e}}$ was found to be much higher than the experimental value. Pseudo secondorder kinetics model was verified with the assumption that the chemisorption follows this kinetics path, which was proposed by Ho and McKay. ${ }^{34}$ The linear form of pseudo-second-order kinetics equation is presented as eqn (8).

$$
t / q_{t}=1 / K_{2} q_{\mathrm{e}}^{2}+t / q_{\mathrm{e}}
$$

where $K_{2}$ is the adsorption rate constant of the pseudo-secondorder model, $q_{\mathrm{e}}$ and $q_{t}$ are the adsorption capacity of mesoporous alumina at equilibrium and time $t$, respectively. The $q_{\mathrm{e}}$ and $K_{2}$ values were obtained from the slope and intercept of the
Table 4 Pseudo first- and second-order kinetics model parameters for adsorption of Congo red

\begin{tabular}{lcllll}
\hline & $\begin{array}{l}\text { Concentration } \\
\left(\mathrm{mg} \mathrm{L}^{-1}\right)\end{array}$ & $\begin{array}{l}Q_{\mathrm{e}, \mathrm{cal}} \\
\left(\mathrm{mg} \mathrm{g}^{-1}\right)\end{array}$ & $\begin{array}{l}Q_{\mathrm{e}, \exp .} \\
\left(\mathrm{mg} \mathrm{g}^{-1}\right)\end{array}$ & $\begin{array}{l}K_{2} \\
\left(\mathrm{mg} \mathrm{g}^{-1} \mathrm{~min}^{-1}\right)\end{array}$ & $R^{2}$ \\
\hline Pseudo & 400 & 399.6 & 399.648 & 0.5 & 1 \\
first- & 500 & 499 & 280 & 0.1456 & 0.73146 \\
order & 750 & 618.75 & 350 & 0.13673 & 0.81928 \\
& 1000 & 599 & 500 & 0.19769 & 0.81056 \\
Pseudo & 400 & 399.6 & 399.65 & 0.5 & 1 \\
second- & 500 & 499 & 510.54 & 0.00177 & 0.99961 \\
order & 750 & 618.75 & 617 & 0.0044 & 0.99748 \\
& 1000 & 599 & 605 & 0.00187 & 0.9984
\end{tabular}

plots of $t / q_{t} v s . t$ (presented in Fig. 14) after fitting the data and shown in Table 4. It is observed that the calculated and observed $q_{\mathrm{e}}$ values do not vary much, and the correlation coefficient $\left(R^{2}\right)$ value of the pseudo-second-order model for all concentration is $\geq 0.99$. From the fitted data we conclude that the experimental observations are consistent with the pseudosecond-order kinetics model instead of the pseudo firstorder model.

\subsection{Adsorption mechanism}

The mechanism of the adsorption of sorbate onto the adsorbent can be described using different ways such as film diffusion, pore diffusion and intra-particle diffusion. Among these processes, the intra-particle diffusion and the pore diffusion are most often the rate limiting steps in a batch reactor. ${ }^{35}$ Therefore, the intra-particle diffusion model has been applied to study the overall adsorption process and the model (Weber and Morris). The equation which satisfies the above adsorption mechanism is shown below: ${ }^{36}$

$$
q_{t}=k_{\mathrm{id}} t^{1 / 2}+C
$$

\begin{tabular}{|c|c|c|c|c|c|}
\hline Samples & \multicolumn{5}{|c|}{ Adsorption results } \\
\hline Boehmite hollow microsphere & 114.7 & 100 & 100 & 100 & 30 \\
\hline $\mathrm{AlOOH}$ microspheres & 319.15 & 20 & 50 & $50-150$ & 32 \\
\hline Nanorod-like mesoporous g- $\mathrm{Al}_{2} \mathrm{O}_{3}$ & 200.1 & 100 & 100 & 100 & 33 \\
\hline Hierarchical hollow g- $\mathrm{Al}_{2} \mathrm{O}_{3}$ & 416.5 & 50 & 50 & $50-500$ & 3 \\
\hline Mesoporous g- $\mathrm{Al}_{2} \mathrm{O}_{3}{ }^{c}$ & 615 & 50 & 50 & $250-1000$ & This study \\
\hline
\end{tabular}

Table 3 Comparison of the maximum adsorption capacities of the sample with different forms of aluminium (oxy)hydroxides for CR removal 


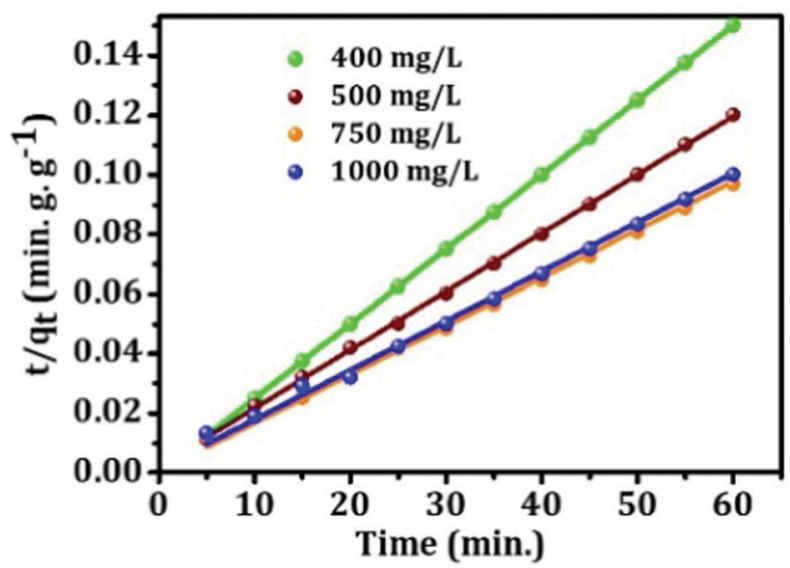

Fig. 14 Plot of pseudo-second-order kinetics equations.

where $q_{t}$ is the amount of Congo red adsorbed at time $t$ $\left(\mathrm{mg} \mathrm{g}^{-1}\right), k_{\text {id }}$ is the initial rate of intra-particle diffusion $\left(\mathrm{mg} \mathrm{g}^{-1} \mathrm{~min}^{-0.5}\right.$ ), and $C$ is the intercept. The nature of the plot gives us an idea about the rate of adsorption steps, such as the plot passing through the origin is an indication that intraparticle diffusion is the rate-controlling step, and if not, the intra-particle diffusion is not only the rate-limiting step but other kinetics models may also control the rate of adsorption. The intra-particle diffusion plot and fitting parameters are given in Fig. 15 and Table. 5, respectively. Fig. 15 shows that the intra-particle adsorption plots are not linear over the whole-

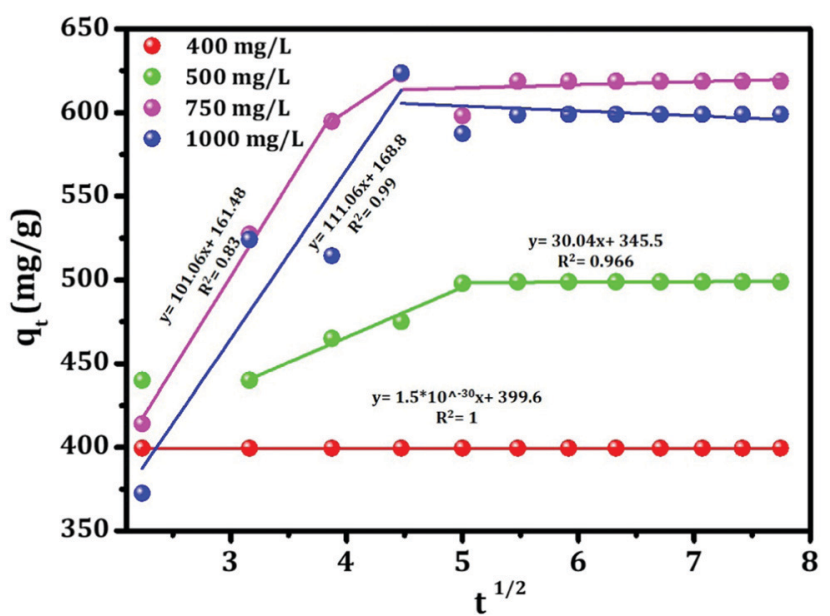

Fig. 15 Intra-particle diffusion for adsorption of Congo red by templatemediated mesoporous alumina.

Table 5 Intra-particle diffusion kinetics constants for adsorption of Congo red

\begin{tabular}{llccc}
\hline \multirow{4}{*}{ Model } & \multicolumn{4}{l}{ At different concentrations } \\
\cline { 2 - 5 } & $400 \mathrm{mg} \mathrm{L}^{-1}$ & $500 \mathrm{mg} \mathrm{L}^{-1}$ & $750 \mathrm{mg} \mathrm{L}^{-1}$ & $1000 \mathrm{mg} \mathrm{L}^{-1}$ \\
\hline$K_{\mathrm{id}}, \mathrm{mg} \mathrm{g}^{-1} \mathrm{~min}^{1 / 2}$ & $1.5 \times 10^{-30}$ & 30.04 & 111.06 & 101.06 \\
$C, \mathrm{mg} \mathrm{g}^{-1}$ & 399.6 & 345.5 & 168.8 & 161.48 \\
$R^{2}$ & 1 & 0.966 & 0.99 & 0.83
\end{tabular}

time range (except $400 \mathrm{mg} \mathrm{L}^{-1}$ ) and no plots of intra-particle diffusion passed through the origin, which indicates that the intra-particle diffusion was not only involved in the ratecontrolling step but was present in the process.

\section{Conclusions}

Hierarchical mesoporous g- $\mathrm{Al}_{2} \mathrm{O}_{3}$ has been successfully synthesized via a hydrothermal process with polysorbate i.e. Tween-40 as the surfactant and a pore forming agent. Polysorbates not only enabled a good dispersion of the sample but also increased the pore volume and surface area after calcination $\left(94 \mathrm{~m}^{2} \mathrm{~g}^{-1}\right)$, which was favourable to improve the adsorption performance of the sample. The product also displayed excellent adsorption capacity for Congo red removal with $Q_{\max }=615 \mathrm{mg} \mathrm{g}^{-1}$ and satisfies the multilayer adsorption isotherm showing $99 \%$ efficiency with a starting concentration of $500 \mathrm{mg} \mathrm{L}^{-1}$ and $60 \%$ efficiency with a starting concentration of $1000 \mathrm{mg} \mathrm{L}^{-1}$. These remarkable properties suggest that the hierarchical mesoporous $\mathrm{g}-\mathrm{Al}_{2} \mathrm{O}_{3}$ can be used as a novel, highly efficient and fast separation sorbent for the removal of organic pollutants from waste water.

\section{Conflicts of interest}

There are no conflicts to declare.

\section{Acknowledgements}

The authors are thankful to Director, CSIR-IMMT, Bhubaneswar, for providing all the facility to carry out the research work.

\section{References}

1 F. Lu, W. Cai and Y. Zhang, Adv. Funct. Mater., 2008, 18, 1047-1056.

2 F. Adeno, E. Mulugeta, F. Zewge and Y. Chebude, Bull. Chem. Soc. Ethiop., 2014, 28(2), 215-227.

3 Z. Li, Y. Du, S. Zhang, Z. Chen, K. Yang, X. Lv and C. Zhu, RSC Adv., 2016, 6, 89699-89707.

4 M. R. Karim, M. A. Rahman, M. A. J. Miah, H. Ahmad, M. Yanagisawa and M. Ito, Open Colloid Sci. J., 2011, 4, 32-36.

5 B. S. B. Reddy, K. Das and S. Das, J. Mater. Sci., 2007, 42(22), 9366-9378.

6 G. Mishra, B. Dash, A. Dash and I. N. Bhattacharya, Cryst. Res. Technol., 2016, 51(7), 433-440.

7 M. Abdollahifar, R. M. Zamani, E. Beiygie and H. Nekouei, J. Serb. Chem. Soc., 2014, 79, 1007-1017.

8 R. Kumar, M. Ehsan and M. A. Barakat, J. Ind. Eng. Chem., 2014, 20, 4202-4206.

9 W. Wang, J. Zhou, Z. Zhang, J. Yu and W. Cai, Chem. Eng. J., 2013, 233, 168-175.

10 A. Telke, D. Kalyani, J. Jadhav and S. Govindwar, Acta Chim. Slovaca, 2008, 55, 320-329. 
11 G. Wang, S. Chen, H. Yu and X. Quan, J. Hazard. Mater., 2015, 299, 27-34.

12 X. Zhang, Y. Wan, C. M. Feng, Y. Shen and D. Y. Zhao, Chem. Mater., 2009, 21, 706-716.

13 V. Uwamariya, B. Petrusevski, Y. Slokar, C. Aubry, P. Lens and G. Amy, Water, Air, Soil Pollut., 2015, 226, 1.

14 M. Purkait, A. Maiti, S. Das Gupta and S. De, J. Hazard. Mater., 2007, 145, 287-295.

15 B. Hameed, A. Ahmad and K. Latiff, Dyes Pigm., 2007, 75, 143-149.

16 M. Bhaumik, R. McCrindle and A. Maity, Chem. Eng. J., 2013, 228, 506-515.

17 Z. Shu, T. Li, J. Zhou, Y. Chen, D. Yu and Y. Wang, Appl. Clay Sci., 2014, 102, 33-40.

18 Z. Shu, Y. Chen, J. Zhou, T. Li, Z. Sheng, C. Tao, D. Yu and Y. Wang, Appl. Clay Sci., 2016, 132-133, 114-121.

19 H. Lu, X. Qiao, W. Wang, F. Tan, Z. Xiao and J. Chen, Desalin. Water Treat., 2015, 56, 256-265.

20 C. Puri and G. Sumana, Appl. Clay Sci., 2018, 166, 102-112.

21 C. Chen, P. Gunawan and R. Xu, J. Mater. Chem., 2011, 21, 1218-1225.

22 S. K. Li, F. Z. Huang, Y. Wang, Y. H. Shen, L. G. Qiu, A. J. Xie and S. J. J. Xu, Mater. Chem., 2011, 21, 7459-7466.

23 S. Ghosh, K. P. Dey and M. K. Naskar, J. Am. Ceram. Soc., 2013, 96, 28.

24 Z. A. ALOthman, Materials, 2012, 5, 2874-2902.
25 C. J. Brinker and G. W. Scherer, Sol-Gel Science: The Physics and Chemistry of Sol-Gel Processing, Academic Press, 2013.

26 C. Lu, J. Lv, L. Xu, X. Guo, W. Hou, Y. Hu and H. Huang, Nanotechnology, 2009, 20, 215604.

27 S. Bi, C. Wang, Q. Cao and C. Zhang, Coord. Chem. Rev., 2004, 248, 441-455.

28 P. Veerakumar, T. Jeyapragasam, Surabhi, K. Salamalai, T. Maiyalagan and K.-C. Lin, J. Chem. Eng. Data, 2019, 64(4), 1305-1321.

29 I. Langmuir, J. Am. Chem. Soc., 1916, 38, 2221-2295.

30 W. Cai, S. Chen, J. Yu, Y. Hu, C. Dang and S. Ma, Mater. Chem. Phys., 2013, 138, 167-173.

31 W. Cai, J. Yu and M. Jaroniec, J. Mater. Chem., 2010, 20, 4587-4594.

32 X. Song, P. Yang, C. Jia, L. Chen and K. Matras-Postolek, RSC Adv., 2015, 5, 33155-33162.

33 W. Cai, Y. Hu, J. Chen, G. Zhang and T. Xia, CrystEngComm, 2012, 14, 972-977.

34 Y. S. Ho and G. McKey, Process Biochem., 1999, 34, 451-465.

35 M. Nadeem, A. Mahmood, S. A. Shahid, A. M. Khalid and G. Mckay, J. Hazard. Mater., 2006, 138(3), 604-613.

36 W. J. Weber Jr. and J. C. Morris, Kinetics of adsorption on carbon from solution, J. Sanit. Eng. Div., Am. Soc. Civ. Eng., 1963, 89, 31-60. 